\title{
Desempenho e coeficiente intestinal de alevinos puros e híbridos de pintados em condicionamento alimentar
}

\author{
Osvaldo Nunes Barbosa ${ }^{1}$, Josué Raizer ${ }^{2}$, Mario Fabiano Gonda ${ }^{3}$, Jesiel Mamedes Silva ${ }^{4}$
}

\author{
1 Pós-Graduando - Mestrado em Biotecnologia - Universidade Católica Dom Bosco (UCDB). \\ 2 Departamento de Biologia da Universidade Federal Grande Dourados (UFGD). \\ ${ }^{3}$ Estação de Piscicultura Projeto Pacu - Terenos, MS. \\ ${ }^{4}$ Departamento de Morfofisiologia - Centro de Ciências Biológicas e da Saúde (CCBS) - Universidade Federal de Matogrosso do Sul (UFMS).
}

RESUMO - Avaliou-se neste estudo o desempenho de alevinos de pintado puros Pseudoplatystoma corruscans e híbridos em treinamento alimentar. O coeficiente intestinal (CI = comprimento do intestino/comprimento total do animal) foi relacionado à massa e ao volume e comparado por meio de análise de variância multivariada e de componentes principais. Conforme a rotina da estação de piscicultura, a duração do condicionamento alimentar é de aproximadamente 60 dias, quando os animais são condicionados a alimentação com ração seca extrusada durante a fase clara do dia. Foram coletados cerca de 100 animais por grupo nas etapas inicial, intermediária e final. No início, os animais receberam coração bovino triturado e gradativamente foi adicionada ração moída até a aceitação de ração seca extrusada ao final. Os crescimentos em extensão e volume corporais dependeram da velocidade de crescimento intestinal. O intestino e a velocidade de adaptação do intestino são maiores nos animais híbridos, o que está associado ao melhor desempenho desses animais.

Palavras-chave: adaptação intestinal, condicionamento alimentar, crescimento, peixes carnívoros, peixes neotropicais, siluriformes

\section{Performance and intestinal coefficient of pure and hybrid hatchlings of Pseudoplatystoma corruscans in feed training}

\begin{abstract}
The performance of pure and hybrid "pintado" Pseudoplatystoma hatchlings at feed training was evaluated. The intestinal coefficient (IC = length of the intestine/total fish lenght) was related to volume and mass and compared by means of analysis of multivariate variance and main components. According to the fish farming station routine, the training lasts about 60 days, when animals are conditioned to feeding on floating dried feed during daylight. Approximately one hundred animals per group were collected in the initial, intermediate and final phases. At the beginning, fish were fed ground bovine heart, and then dried feed was gradually added until eventual acceptance of dried floating feed. Length and volume growth depended on the speed of intestinal growth. The intestine and the time of adaptation of the intestines are longer in hybrid animals, which is linked to the better development of these animals.
\end{abstract}

Key Words: alimentary conditioning, carnivorous fish, catfish, growth, intestinal adaptation, neotropical fish

\section{Introdução}

No ambiente natural o pintado (Pseudoplatystoma corruscans) e o surubim-cachara (Pseudoplatystoma fasciatum) são reófilos predominantemente piscívoros, de hábitos noturnos e demersais (Rezende et al., 1995; Godinho, 1997). Apresentam excelente qualidade de carcaça e características zootécnicas (Martino et al., 2002), mas a viabilidade econômica do seu cultivo depende do condicionamento alimentar dos alevinos para alimentação com ração seca à superfície e durante a fase clara do dia.

O coeficiente intestinal pode variar conforme a dieta (Al-Hussaini, 1949), refletindo a adaptação do trato digestivo ao hábito alimentar (Bertin, 1958). Está relacionado à filogenia, ao estado trófico (Kapoor et al., 1975) e ao estresse por restrição de espaço (Barrington, 1957). O crescimento dos peixes pode variar em ciclos alternados em extensão, massa e períodos de alta e baixa velocidade e depende de fatores intrínsecos e extrínsecos (Mommsen, 2001), mas pouco se conhece sobre as variações morfométricas do intestino de alevinos de pintados durante o condicionamento alimentar ou sobre as implicações no desempenho desses animais.

Na fase de alevino, a dieta natural do pintado é constituída principalmente por zooplâncton, como os cladóceras (89,24\%) e chironomidae (10,76\%) (Marques, 1997). Na fase 
juvenil, o intestino do pintado é relativamente curto e adaptado à dieta carnívora (Seixas \& Filho, 2001). Machado et al. (2003) observaram que o nível ideal de proteína na dieta do pintado depende de suas necessidades energéticas, cujas variações podem provocar discretas adaptações morfológicas das vilosidades intestinais e fisiológicas, como a ação da amilase (Lundspect et al., 2004). O aumento energético, isoladamente, não garante melhor desempenho ou qualidade de carcaça (Martino et al., 2005).

Os objetivos neste estudo foram observar as variáveis morfométricas massa, volume, comprimento padrão, comprimento intestinal e o coeficiente intestinal de alevinos de pintado puros e de híbridos coletados no início, meio e fim do treinamento alimentar e verificar a relação entre o coeficiente intestinal e o desempenho.

\section{Material e Métodos}

Foram utilizados 589 alevinos de pintado, de ambos os sexos, irmãos maternos, sendo 306 puros de Pseudoplatystoma corruscans e 283 híbridos dessa espécie com Pseudoplatystoma fasciatum, oriundos da estação de Piscicultura Projeto Pacu, Terenos, Mato Grosso do Sul, Brasil.

As coletas aconteceram no início, na metade após 30 dias e ao final, após 60 dias, do condicionamento alimentar, quando os animais apresentavam aproximadamente 30 , 60 e 90 dias de idade, respectivamente. Foram coletados aleatoriamente 100, 104 e 102 exemplares puros e 81, 98 e 104 híbridos, conforme as respectivas etapas. As colheitas aconteceram no período da manhã e, em seguida, os animais foram sacrificados por secção da medula espinhal, imediatamente após a região occipital, conforme descrição de Seixas et al. (2001). Após a morfometria, os animais foram identificados e armazenados em solução de formalina a $4 \%$.

Conforme a rotina da Estação de Piscicultura Projeto Pacu, no início do condicionamento alimentar, animais de 4 a $6 \mathrm{~cm}$ tamanho são deslocados de tanques de terra, a céu aberto, com dieta planctônica para raceway de $40 \mathrm{~m}^{3}$, retangulares, na densidade de 4 animais/L em galpões cobertos. Na primeira semana, os animais passaram a receber coração bovino moído de 4 em 4 horas. Na segunda semana, foi adicionada à dieta ração balanceada comercial seca destinada para peixes ictiófagos. A ração, com $40 \%$ de proteína bruta, foi triturada juntamente com o coração e oferecida na forma de péletes na proporção de $10 \%$ da dieta total.

O percentual de ração foi aumentado gradativamente de maneira que aos 30 dias, na fase intermediária, a dieta passou a ser constituída de proporções semelhantes (1:1) de coração e ração, oferecida de 6 em 6 horas. Ao final do condicionamento, os animais já se alimentavam exclusivamente de ração comercial extrusada duas vezes no período diurno. Depois da primeira semana, a oferta diária de alimento foi de $5 \%$ do peso vivo.

A massa dos animais de cada coleta foi aferida por meio de balança de precisão e o volume do animal foi determinado indiretamente, por meio da massa do volume da água destilada deslocada pelo corpo do animal fresco. O comprimento padrão e o comprimento intestinal foram medidos com auxílio de paquímetro e o coeficiente intestinal foi obtido por meio da relação $\mathrm{CI}=\mathrm{Ci} / \mathrm{Cp}$, conforme descrição de Bertin (1958).

Para se obter um gradiente representativo da variação de características morfométricas dos peixes amostrados e relacionar o comprimento intestinal e o desempenho, padronizou-se o valor de cada variável amostral, dividindose pela raiz quadrada da soma dos quadrados das respectivas variáveis. Utilizaram-se as análises de variância multivariada e de componentes principais e o teste de Pillai Trace (Legendre \& Legendre, 1998), com o índice de correlação como medida de associação entre os pares de peixes e o teste de comparações múltiplas de Tukey para as fases do treinamento. As variáveis morfométricas consideradas para a análise dos componentes principais foram volume $\left(\mathrm{cm}^{3}\right)$, massa (g), comprimento padrão $(\mathrm{cm})$, comprimento do intestino $(\mathrm{cm})$ e coeficiente intestinal (cm). Para retirar o efeito do peso das variáveis nas amostras, elas foram padronizadas por meio da divisão pela raiz quadrada da soma dos quadrados de cada variável. As diferenças entre os híbridos e puros, as etapas do treinamento e as interações desses fatores foram consideradas significantes, com $\mathrm{P}<0,05$.

\section{Resultados e Discussão}

No condicionamento alimentar de alevinos híbridos e puros de pintado, as variáveis morfométricas massa, volume, comprimento padrão, comprimento intestinal e coeficiente intestinal com valores médios maiores variaram de forma semelhante (Tabela 1), o que corrobora as observações sobre a viabilidade do condicionamento de alevinos de pintado (Hayashi et al., 1999).

O número de eixos da análise dos componentes principais explicou pelo menos 95\% da variância total no espaço n-dimensional gerado pela matriz de correlação entre as amostras. A variação morfométrica dos peixes, representada pelos dois primeiros eixos da análise de componentes principais foi significativamente explicada pelo tipo de peixe (Pillai Trace $=0,628 ; \mathrm{F}=490,322$; 
gl $=3$ e 582; $\mathrm{P}<0,001$ ), pelas fases do treinamento (Pillai Trace $=1,022 ; \mathrm{F}=304,386 ; \mathrm{gl}=4$ e $1166 ; \mathrm{P}<0,001$ ) e pela interação desses fatores (Pillai Trace $=0,647 ; \mathrm{F}=139,416$; $\mathrm{gl}=4$ e $1166 ; \mathrm{P}<0,001)$.

Os vetores indicaram contribuição relativa das variáveis massa e volume comprimento padrão, comprimento intestinal e coeficiente intestinal, consideradas na ordenação das amostras, por análise dos componentes principais. O gradiente de variação da morfometria intestinal foi representado pelos dois primeiros eixos da análise de componentes principais, que explicaram $97,42 \%$ da variância total em todas as fases do condicionamento alimentar, sendo $74,73 \%$ no primeiro eixo (autovalor $=3,74$ ) e 22,69\% no segundo eixo (autovalor $=1,13)$ (Figura 1). Ao final do treinamento, o primeiro eixo de ordenação explicou 76,55\% da variância (autovalor $=3,87$ ) e o segundo, 21,55\% (autovalor $=1,077$ ) (Figura 2).
Híbridos
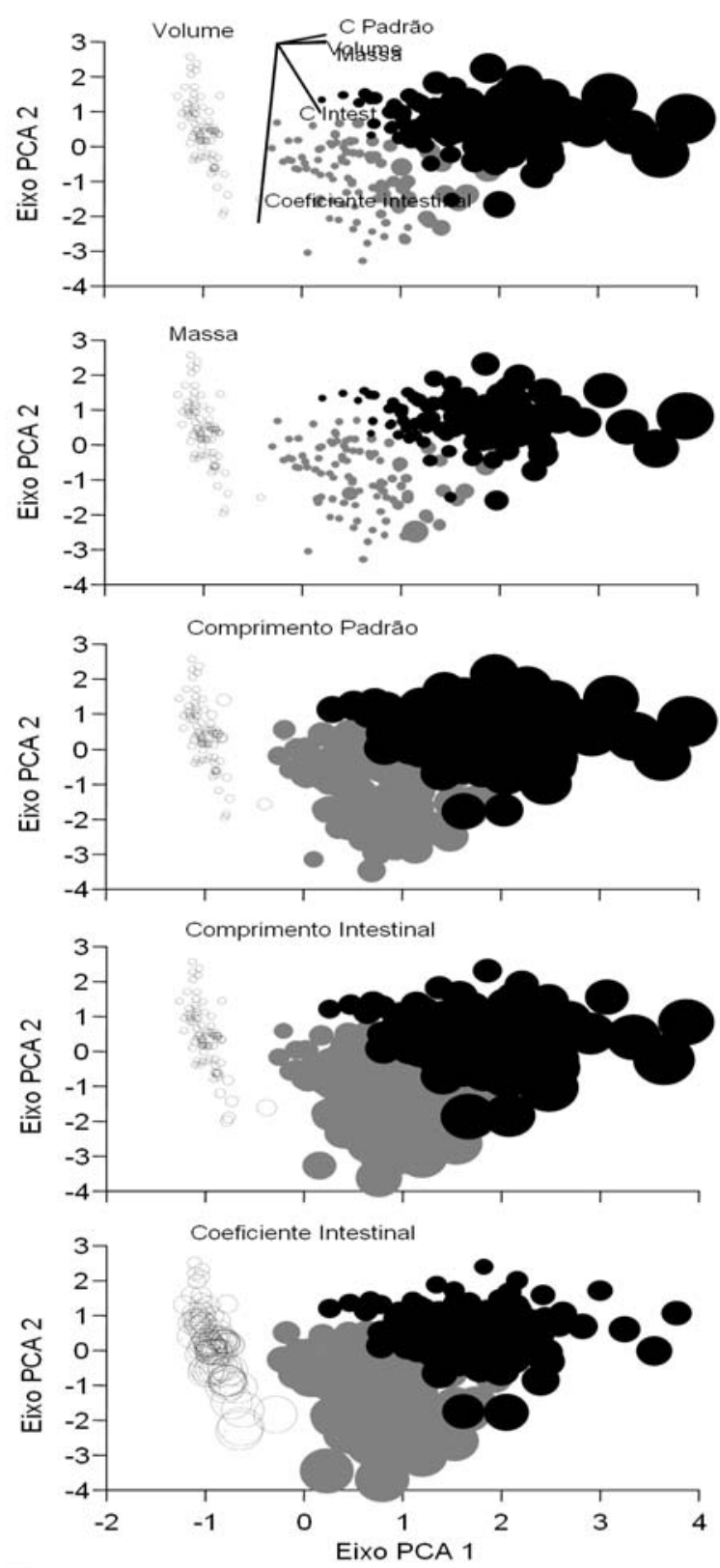

Puros
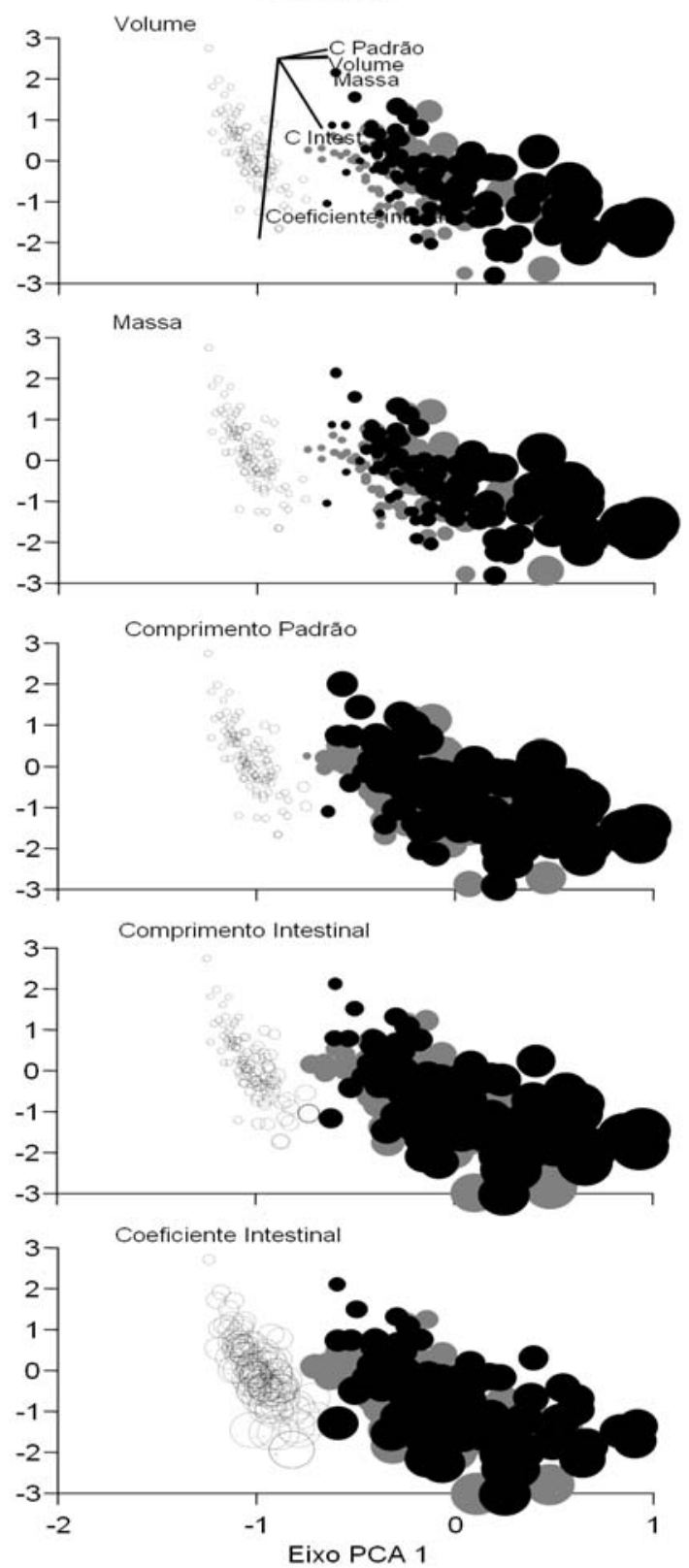

No plano da ordenação definida pelos dois primeiros eixos da análise de componentes principais, entre animais nas fases inicial (pontos vazios), intermediária (pontos cinza) e final (pontos pretos) do treinamento alimentar. O tamanho dos pontos é direta e positivamente relacionado às variáveis morfométricas volume (cm ${ }^{3}$ ), massa (g), comprimento padrão, comprimento intestinal e coeficiente intestinal.

Figura 1 - Variáveis morfométricas de alevinos híbridos e puros de pintados durante o condicionamento alimentar. 


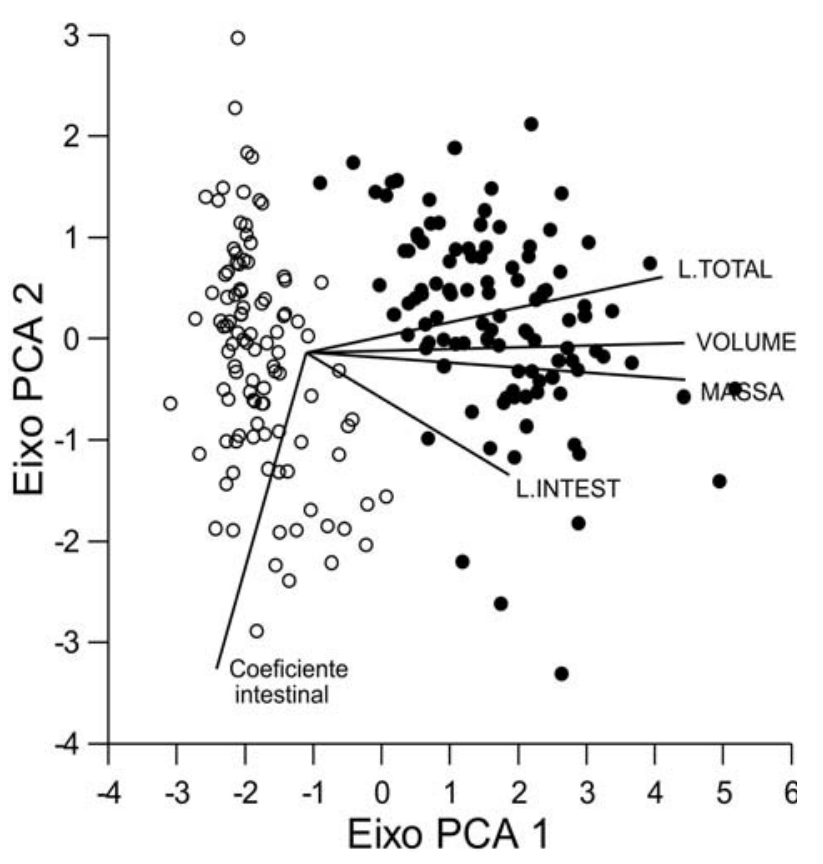

Os alevinos puros estão representados por pontos vazios e os híbridos por pontos cheios. O primeiro eixo da ordenação (coeficiente intestinal) explicou 76,55 \% da variância (eigen $=3,827$ ) e o segundo (comprimento intestinal), $21,55 \%$ (eigen=1,077). Os vetores indicam a contribuição relativa das variáveis consideradas na ordenação.

Figura 2 - Ordenação das amostras por análise de componentes principais ao final do condicionamento alimentar.

As características morfométricas dos peixes híbridos ou puros na primeira coleta, quando fornecida a dieta composta apenas por coração bovino, foram distintas da segunda e terceira coletas, na metade e no final do condicionamento alimentar, respectivamente, o que é comprovado principalmente pelo primeiro eixo da ordenação. Isso se deve às contribuições relativas de massa e volume comprimento padrão e comprimento intestinal, cujas variáveis morfométricas explicaram melhor as diferenças entre os animais híbridos e puros nessa fase (Figura 1).

Os valores médios das variáveis morfométricas volume, massa, comprimento padrão e comprimento intestinal aumentaram entre o início e a metade do condicionamento alimentar dos híbridos e puros, porém isso aconteceu de maneira mais acentuada nos híbridos, o que comprova melhor ganho em desempenho dos híbridos nos primeiros 30 dias de treinamento. Neles, o volume, a massa e o comprimento padrão continuaram a aumentar ao longo do condicionamento, enquanto nos puros não houve diferenças significativas. O comprimento intestinal dos híbridos foi menor que o dos puros no início do treinamento, enquanto o coeficiente intestinal dos animais puros não mudou ao longo do treinamento. Nos híbridos, esse parâmetro foi significativamente maior na fase intermediária, diminuindo na fase final, tornando-se semelhante aos valores observados na fase inicial, semelhante ao dos puros na mesma fase (Figura 2). Isso comprovou maior plasticidade intestinal dos híbridos no condicionamento alimentar.

Houve grande sobreposição na amplitude das variáveis dos peixes puros nas fases intermediária, quando os animais recebiam ração e coração na proporção 1:1, e final do condicionamento, quando a dieta era constituída de $100 \%$ de ração comercial. Os coeficientes intestinais dos alevinos puros foram semelhantes nessas coletas. Já nos híbridos, esse índice foi maior na segunda coleta (Tabela 1; Figura 1), sugerindo que o crescimento intestinal foi determinante na adaptação desses animais.

Exceto o coeficiente intestinal, os maiores valores médios das demais variáveis morfométricas, de híbridos e puros, aumentaram da metade para o final do condicionamento, mas a amplitude das variáveis dos peixes puros demonstrou

Tabela 1 - Morfometria de alevinos híbridos e puros de pintado (Pseudoplatystoma corruscans) nas fases inicial, intermediária e final do condicionamento alimentar

\begin{tabular}{|c|c|c|c|}
\hline \multirow[t]{3}{*}{ Fonte de variação } & \multicolumn{3}{|c|}{ Tipo de alevino } \\
\hline & \multicolumn{3}{|c|}{ Híbridos } \\
\hline & Fase inicial $(\mathrm{n}=81)$ & Fase intermediária $(\mathrm{n}=98)$ & Fase final $(n=104)$ \\
\hline Volume $\left(\mathrm{cm}^{3}\right)$ & $0,23 \pm 0,10 \quad(0,07-0,74)$ & $2,29 \pm 0,89 \quad(0,81-5,38)$ & $4,99 \pm 1,50 \quad(2,00-9,46)$ \\
\hline Massa (g) & $0,26 \pm 0,10 \quad(0,10-0,80)$ & $2,27 \pm 0,94 \quad(0,76-5,65)$ & $4,84 \pm 1,5 \quad(1,89-10,83)$ \\
\hline Comprimento padrão $(\mathrm{cm})$ & $0,82 \pm 0,12 \quad(0,55-1,23)$ & $2,15 \pm 0,29 \quad(1,51-3,03)$ & $2,98 \pm 0,31 \quad(2,20-3,78)$ \\
\hline Comprimento intestinal (cm) & $0,74 \pm 0,19 \quad(0,25-1,51)$ & $2,45 \pm 0,46 \quad(1,46-3,37)$ & $2,66 \pm 0,43 \quad(1,66-3,86)$ \\
\hline \multirow[t]{2}{*}{ Coeficiente intestinal } & $1,55 \pm 0,28 \quad(0,89-2,28)$ & $1,94 \pm 0,27 \quad(1,45-2,61)$ & $1,51 \pm 0,18 \quad(1,10-2,19)$ \\
\hline & \multicolumn{2}{|r|}{ Puros } & Fase final $(\mathrm{n}=102)$ \\
\hline Volume $\left(\mathrm{cm}^{3}\right)$ & $0,18 \pm 0,05 \quad(0,09-0,36)$ & $0,97 \pm 0,31 \quad(0,39-2,15)$ & $1,17 \pm 0,48 \quad(0,40-2,77)$ \\
\hline Massa (g) & $0,14 \pm 0,05 \quad(0,01-0,33)$ & $1,07 \pm 0,33 \quad(0,54-2,15)$ & $1,25 \pm 0,51 \quad(0,42-2,96)$ \\
\hline Comprimento padrão $(\mathrm{cm})$ & $0,79 \pm 0,09 \quad(0,55-1,05)$ & $1,55 \pm 0,17 \quad(0,85-2,00)$ & $1,69 \pm 0,22 \quad(1,12-2,25)$ \\
\hline Comprimento intestinal (cm) & $0,76 \pm 0,16 \quad(0,38-1,18)$ & $1,62 \pm 0,28 \quad(1,12-2,56)$ & $1,76 \pm 0,39 \quad(0,93-2,77)$ \\
\hline Coeficiente intestinal & $1,62 \pm 0,24 \quad(0,83-2,19)$ & $1,77 \pm 0,22 \quad(1,27-2,46)$ & $1,77 \pm 0,26 \quad(1,01-2,46)$ \\
\hline
\end{tabular}


grande sobreposição entre as fases intermediária e final do condicionamento alimentar. Já o coeficiente intestinal dos puros foi semelhante nessas duas fases, e o dos híbridos foi maior na fase intermediária (Tabela 1; Figura 3). Assim, o maior comprimento relativo do intestino dos híbridos viabilizou o ganho em desempenho nos últimos 30 dias do condicionamento alimentar.

Entretanto, nos peixes híbridos, o tamanho, o volume e a massa explicaram as diferenças entre os maiores peixes ao final e os menores peixes na fase intermediária. Além disso, os menores peixes puros ao final do treinamento não diferiram em tamanho dos peixes da fase inicial. Isso comprova que o lote dos animais híbridos foi mais uniforme, portanto, de mais fácil manejo.

Nos híbridos, o comprimento padrão e o comprimento intestinal foram maiores na fase intermediária e apresentaram velocidade de crescimento semelhante nos primeiros trinta dias de condicionamento. Contudo, a associação dessas variáveis para formar o coeficiente intestinal (comprimento intestinal/comprimento padrão) contribuiu para diferenciar os peixes maiores da fase intermediária dos peixes menores ao final do treinamento. Todavia, o coeficiente intestinal não explicou qualquer diferença entre os peixes puros, portanto, esse parâmetro é essencial na determinação do fator de condição desses peixes.

Ao final do condicionamento alimentar, os animais puros não apresentaram diferenças significativas em relação à fase anterior. Por outro lado, a análise de componentes principais comprovou que os peixes híbridos apresentaram características morfométricas distintas dos demais grupos, e essa diferença foi causada pelo efeito integrado entre o coeficiente intestinal e as variáveis massa, volume, comprimento padrão e/ou comprimento intestinal (Figuras 1 e 2). Isso reforça a hipótese de que esses animais apresentaram melhor adaptação intestinal na fase de condicionamento, o que distingue os tipos de alevinos quanto ao desempenho. O coeficiente intestinal de siluriformes carnívoros também pode diminuir da idade de alevinos para a fase adulta (Basilie-Martin, 1978; Das \& Srivastara, 1979).

Lundsted et al. (2004) observaram que, em pintados, a área absortiva e a atividade da amilase podem variar conforme a dieta. Por outro lado, proteínas bioativas e termoestáveis do plasma sanguíneo estimulam a ingestão de alimentos, a conversão alimentar, a retenção de nitrogênio e o crescimento do animal, mas inibem o catabolismo (Jiang et al., 2000; Kats et al., 1994 a, b); provocam atrofia intestinal (Thompson et al., 1989) e atrasam a renovação celular no epitélio do intestino (Jiang et al., 2000). O fator de crescimento e transformação beta (TGF- $\beta$ ) é conservado filogeneticamente, inibe a proliferação celular do epitélio intestinal, é termoestável (Ko et al., 1997) e induz a apoptose de enterócitos (Dünker et al., 2002).

O aumento da proporção de ração seca em relação ao coração bovino triturado de 50 a $100 \%$ na fase final do condicionamento alimentar foi associado à redução do tamanho intestinal dos animais híbridos, tanto em extensão como relativamente (Figuras 1 e 2). Isso poderia estar relacionado à maior susceptibilidade às substâncias exógenas inibidoras incorporadas à ração. Portanto, neste trabalho o comprimento e o coeficiente do intestino podem tanto aumentar como diminuir ao longo do condicionamento e sua plasticidade morfológica é maior em alevinos híbridos. Isso poderia ser explorado no sistema de cultivo intensivo. O estudo sobre a expressão dos receptores para o TGF- $\beta$ pelo epitélio intestinal, bem como o transcriptoma

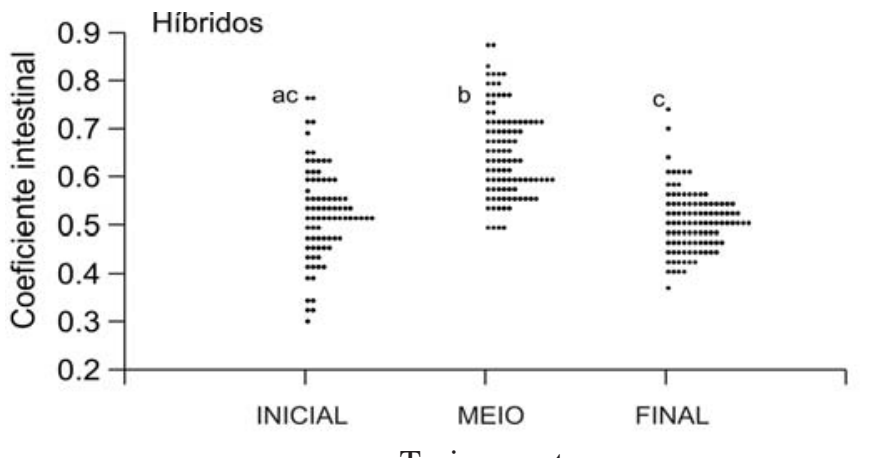

Treinamento

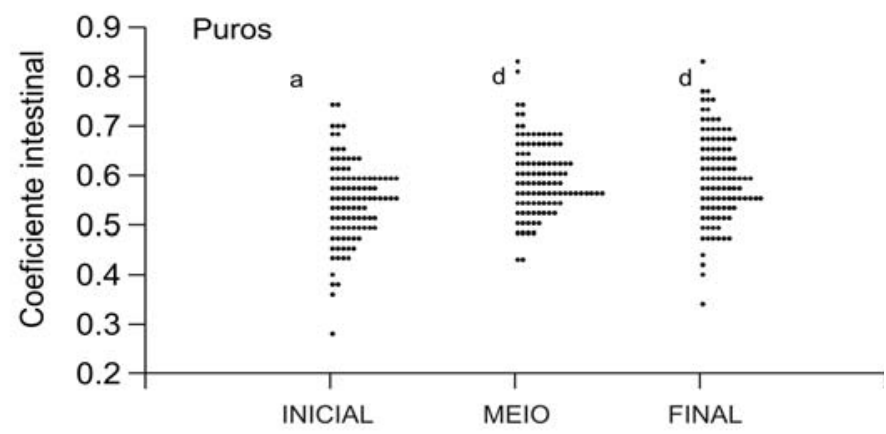

Treinamento

Nas letras iguais o índice intestinal não diferiu significativamente $(\alpha<0,05)$ entre as fases (Teste de comparações múltiplas de Tukey). A análise de variância por ANOVA e o teste de Tukey, revelaram que o índice intestinal variou significativamente entre os tipos de peixes $(\mathrm{F}=0,241$ e $\mathrm{P}=0,004)$, as fases de treinamento $(\mathrm{F}=66,011 ; \mathrm{P}<0,001)$ e a interação desses fatores $(\mathrm{F}=39,408 ; \mathrm{P}<0,001)$.

Figura 3 - Variação do coeficiente intestinal de animais híbridos e puros nas fases inicial, intermediária e final do treinamento alimentar de alevinos de pintado. 
dos tecidos do intestino no treinamento alimentar, esclareceria melhor o mecanismo de controle de crescimento desse órgão.

Nos animais híbridos, o volume, a massa e o comprimento padrão continuaram a aumentar ao longo do treinamento, enquanto, nos puros, não houve diferenças significativas. O comprimento intestinal dos híbridos foi menor que o dos puros no início do treinamento, enquanto o coeficiente padrão dos animais puros não mudou ao longo do condicionamento. Nos híbridos, esse parâmetro foi significativamente maior na fase intermediária e diminui na fase final, tornando-se semelhante ao observado na fase inicial, semelhante ao dos puros na mesma fase (Figura 3). Isso comprovou maior plasticidade intestinal dos híbridos no condicionamento alimentar. Jiang et al. (2000) sugeriram que o fibrinogênio e as globulinas do plasma inibem o desenvolvimento intestinal. As características do fator de crescimento e transformação beta (TGF- $\beta$ ) já citadas dão apoio à hipótese de que este fator também poderia mediar esse efeito.

Exceto o coeficiente intestinal, os maiores valores médios das demais variáveis morfométricas, de híbridos e puros, aumentaram da fase intermediária para a final (Tabela 1; Figuras 1 e 3), mas a amplitude das variáveis dos peixes puros comprovou grande sobreposição entre as fases intermediária e final do condicionamento alimentar. Já o coeficiente intestinal dos puros foi semelhante nessas duas fases e o dos híbridos foi maior na fase intermediária. Assim, o maior comprimento relativo do intestino dos híbridos viabilizou o ganho em desempenho nos últimos 30 dias do condicionamento alimentar. Entretanto, nos peixes híbridos, o tamanho (volume e massa) explicou as diferenças entre os maiores peixes ao final e os menores peixes na fase intermediária. Além disso, os menores peixes puros ao final do treinamento não diferiram em tamanho daqueles da fase inicial, revelando que o lote dos animais híbridos foi mais uniforme e, portanto, de mais fácil manejo.

\section{Conclusões}

O crescimento de alevinos de pintado híbridos e puros depende do crescimento intestinal. Animais híbridos apresentam maior velocidade de crescimento intestinal, o que lhes permite obter melhor desempenho ao final do condicionamento alimentar. Os híbridos possuem também maior plasticidade intestinal, tanto para o crescimento como para a redução desse órgão no condicionamento alimentar.

\section{Agradecimentos}

Ao Sr. Jaime Brun, pela disponibilização das instalações da Estação de Piscicultura Projeto Pacu, em Terenos, Mato Grosso do Sul, Brasil, e pela doação dos exemplares utilizados neste estudo.

\section{Referências}

AL-HUSSAINI. On the functional morphology of the alimentary tract of some fish in relation to difference in their feeding habits. Anatomy and Histology. Quartely Journal Microscopy Science, v.90, p.109-140, 1949.

BARRINGTON, E.J.W. The alimentary canal and digestion. In: BROWN M.E. (Ed.) The physiology of fishes. New York: Academic Press, 1957. v.1, p.109-161.

BASILE-MARTINS, M.A. Comportamento e alimentação de Pimelodus maculatus Lacépède, 1803 (Osteichthyes, Siluriformes, Pimelodidae). 1978. 103f. Tese (Doutorado em Ciências) - Instituto de Biociências/Universidade de São Paulo, São Paulo.

BERTIN I. Appareil digestif. In: GRASSE, P.P. (Ed.) Traité de zoologia. Paris: Masson, 1958. v.13, p.302-1248.

DAS, S.M.; SRIVASTARA, A.K. On the relative length of gut (RLG) in some food fishes of Uttar Pradesh with changes from fingerling to adult stage. Journal of Inland Fisheries Society of India, v.11, n.1, p.6-11, 1979.

DÜNKER N.; SCHIMIOT K.; SCHUSTER N. et al. The role of transforming growth factor beta-z, beta-s in mediating apoptosis in the murine intestinal mucosa. Gastroenterology, v.122, p.1364-1375, 2002.

GODINHO, H.P. Pesca e biologia do surubim Pseudoplatystoma corruscans das bacias dos rios São Francisco e Paraguai. In: MIRANDA, M.O.T. (Ed.) Surubim. Belo Horizonte: Instituto Brasileiro do Meio Ambiente e dos Recursos Naturais Renováveis, 1997. v.19, p.27-42 (Coleção Meio Ambiente, Série Estudos de Pesca)

HAYASH, I.C.; GONÇALVES, G.S.; FURUYA, V.R.B. et al. Utilizações de diferentes alimentos durante o treinamento de alevinos de pintado (Pseudoplatystoma corruscans) (Agassiz, 1829). Aquaculture, v.1, p.258-267, 1999.

JIANG, R.; CHAN, G.X.; STOLL, B. et al. Biochemical and molecular action of nutrients. Dietary plasma protein reduces small intestinal growth and lamina propria cell density in early weaned pigs. Journal of Nutrition, v.130, p.21-26, 2000.

KAPOOR, B.G.; SMITH, H.; VEREGINA, I.A. The alimentary canal and digestion in teleosts. Advances in Marine Biology, v.13, p.109-239, 1975.

KATS, L.J.; NELSSEM, J.L.; TOKACH, M.D. et al. The effect of spray-dried porcine plasma on growth performance in the earlyweaned pig. Journal of Animal Science, v.72, p.2075-2081, 1994a.

KATS, L.J.; NELSSEM, J.L.; TOKACH, M.D. et al. The effect of spray-dried blood meals on growth performance in the early-weaned pig. Journal of Animal Science, v.72, p.2060-2069, 1994b.

KO, T.C.; BRESNAHAN, W.A.; THOMPSO, N.E.A. Intestinal cell cycle regulation. Progress in Cell Cycle Research, v.3, p.43-52, 1997.

LUNDSTEDT, L.M.; MELO, J.F.B.; MORAES, G. Digestive enzymes and metabolic profile of Pseudoplatystoma corruscans (Teleostei: Siluriformes) in response to diet composition. Comparative Biochemistry and Physiology - Part B, v.137, p.331-339, 2004.

KUBITZA, F.; CAMPOS, J.L.; BRUM, J.A. Surubim: produção intensiva no Projeto Pacu Ltda. e Agropeixe Ltda. Panorama da Aquacultura, v.49, p.25-32, 1998. 
MACHADO, J.H.; CARRATORE, C.R.; LANDELL-FILHO, L.C et al. Desempenho produtivo de pintado (Pseudoplatystoma corruscans) arraçoados com diferentes níveis de proteína e energia. Unimar Ciências, v.8, p.87-98, 1999.

MARQUES, E.E. Biologia reprodutiva, alimentação natural e dinâmica da nutrição do pintado Pseudoplatystoma corruscans Agassiz, 1829 (Osteichthyes, Pimelodidae) no alto rio Paraná. 1997. 104f. Dissertação (Mestrado) Universidade Federal do Paraná, Curitiba.

MARTINO, R.C.; CYRINO, J.E.P.; PORTZ, L. et al. Performance and fatty acid composition of surubim (Pseudoplatystoma corruscans) fed diets with animal and plant lipids. Aquaculture, v.209, p.233-246, 2002.

MATINO, R.C.; CYRINO, J.E.P.; POLTZ, L. et al. Performance carcass composition and nutrient utilization of surubim Pseudoplatystoma corruscans (Agassiz) fed diets with varying carboidrate and lipid levels. Aquaculture Nutrition, v.11, p.131-137, 2005.

MOMMSEN, T.P. Review - Paradigms of growth in fish. Comparative Biochemistry and Physiology - Part B, v.129, p.207-219, 2001.

RESENDE, E.K. Trophic struture of fish assemblages in lower Miranda river, Pantanal, Mato Grosso do Sul state, Brasil. Revista Brasileira de Biologia, v.60, n.3, p.389-403, 2000. Disponível em: <http://dx.doi.org/10.1590/S0034-71082000000300004>.

SEIXAS, J.T.F.; BRÁS, J.M.; GOMIDE, A.T.M. et al. Anatomia funcional e morfometria do intestino no Teleostei (Pisces) de Água Doce Surubim (Pseudoplatystoma coruscans - Agassiz, 1829). Revista Brasileira de Zootecnia, v.30, n.6, p.1670-1680, 2001.

THOMPSON, J.S; SAXENA, S.K.; SHARP, J.G. Effect of eflorithine on intestinal regeneration. Archives of Surgery, v.124, n.4, p.454-457, 1989. 